\title{
Carlos F. Clamote Carreto Épiphanies symboliques. Masque, altérité et fictions identitaires dans la chanson de geste
}

\section{SYMBOLIC EPIPHANIES. MASK, OTHERNESS AND} Fictions OF IDENTITY IN THE CHANSON DE GESTE Abstract: Far from being a monochromatic discourse that stands in secular liturgy celebrating the eternal return of the Same, the chanson de geste is a dynamic structure in perpetual tension between myth and history, between the symbolic and the semiotic, or between the imaginary and ideology. In this perspective, the encounter with the Other (Saracen, Infidel or traitor) does not always arise from a simple radical bipolarization of values; it involves a triple movement of deconstruction, exchange and transformation in poetic and ontological terms.

Keywords: French Medieval Literature; Epic Imaginary; Representations of Otherness; Myth, History and Literature; Mask, Fiction and Identity.

\section{Carlos F. Clamote Carreto}

Universidade Nova de Lisboa, Portugal ccarreto@fcsh.unl.pt

DOI: $10.24193 /$ cechinox.2019.37.17
Muat sa veie e changat sun latin, Salamoneis parlat, tieis e barbarin, Grezeis, alemandeis, aleis, hermin, $E$ les langages que li bers [Guillaume] out ainz apris.

La Chanson de Guillaume, v. $2169-2172^{1}$

La littérature est un vaste laboratoire où sont essayés des estimations, des évaluations, des jugements d'approbation et de condamnation par quoi la narrativité sert de propédeutique à l'étbique.

P. Ricœur, Soi-même comme un autre, p. $139^{2}$

\section{L'Autre et l'impensable : un défi}

\section{à la représentation}

T 'altérité, le regard qu'un individu porte Lur autrui, un groupe, voire une civilisation entière à un moment donné de son évolution, est sans doute l'un des enjeux les plus complexe, redoutable et problématique de toute construction imaginaire, l'Autre se dessinant toujours à la croisée des images 
fabriquées par un triple miroir presque superposé : l'image (idéalisée ou menacée) du sujet projetée sur autrui, l'image du sujet renvoyée par autrui et l'image que l'on croit percevoir à travers le regard porté par autrui sur nous-même. Autrement dit, la construction de l'identité dans son rapport dialectique à l'altérité (les deux faces indissolubles de notre rapport au monde) est sans cesse modélisée par des faisceaux multidirectionnels de représentations formés par des images (matérielles ou mentales, visuelles ou langagières, objectives ou subjectives mais toujours sensibles, oniriques, poétiques et affectives, symboliques ou archétypales, mais toujours cognitives ${ }^{3}$ ) qui tissent un récit pluriel sur soi-même et sur l'Autre aux contours extrêmes plastiques et changeants, voire contradictoires et conflictuels.

La nature dialectique de l'identité et de l'altérité confère notamment à cette dernière un caractère polysémique et un statut extrêmement ambigu car l'altérité qui repose toujours, comme nous venons de le constater, sur des systèmes de représentations réglés par des instances symboliques - n'est jamais ni une donnée objective ${ }^{4}$, ni une donnée entièrement subjective et abstraite qui ferait de l'Autre le lieu vide - ou la forme vide - de l'affirmation identitaire. Toute réflexion sur l'altérité pose également des problèmes épistémologiques délicats : comment concevoir « l'absolument autre $\aleph^{5}$ en dehors d'une part de tout jeu de miroir ${ }^{6}$ et en dehors de toutes les méta-catégories qui au moins depuis l'Antiquité grecque ${ }^{7}$ modèlent notre pensée occidentale de lêtre qui tend à fonder, dans les domaines les plus divers (de la littérature à la philosophie, en passant par la psychologie sociale, la sociologie ou l'anthropologie) notre rapport à tout ce qui nous entoure sur un processus cognitif construit sur des oppositions structurantes entre le proche et le lointain, le centre et la périphérie, l'identique et le différent, le semblable et le dissemblable, l'un et le multiple, le modèle et la copie, le moi et le nonmoi, la Forme et l'informe ou le difforme, etc. C'est dire que notre tendance (ancrée sans doute aussi bien sur des fondements phylogénétiques qu'anthropologiques et culturels) nous pousse à organiser et à lire le monde suivant des classements hiérarchiques qui accentuent les dichotomies et mettent plus en valeur la distance, le hiatus et la frontière que le cheminement, la réciprocité des consciences et des regards, les zones poreuses de confluence et d'hybridation. Et si nous avons trop souvent " les yeux rivés sur la rupture », comme le soulignait lucidement Thierry Hentsch dans son article sur « L'altérité dans l'imaginaire occidental : fonction manifeste, fonction occulte $»^{8}$, c'est que nous sommes aveugles à notre propre regard :

À proprement parler, d'ailleurs, ce regard, le nôtre, est ce qu'il y a pour nous de plus radicalement irregardable. C'est ce que nous ne verrons jamais de nous. Car le regard que nous observons dans le miroir ne peut que se regarder soi-même dans l'acte de se regarder, sans du tout surprendre notre regard sur le monde. Le miroir est un trompe-l'œil. Ce n'est donc que dans le regard de l'Autre que nous pouvons déchiffrer quelque chose de notre regard sur le monde. ${ }^{9}$

Conscient de cet aveuglement et de l'aporie herméneutique à laquelle il peut 
nous conduire, relevons cependant le défi choisissant toutefois le terrain un peu plus circonscrit mais non moins instable, risqué et révélateur du point de vue éthique de la fiction littéraire ${ }^{10}$ et, plus précisément, de la chanson de geste médiévale. Partir de ce corpus pour penser l'imaginaire (ou les imaginaires) de l'altérité n'est pas un choix anodin, car la poésie qui émerge à partir du $\mathrm{XI}^{\mathrm{e}}$ siècle participe entièrement d'un imaginaire du seuil où l'identité se fonde sur une dynamique du transfert (poétique et politique de la translatio), de la greffe, de l'intégration et de la transmutation d'une série d'éléments qui relève, au départ, d'un rapport d'altérité. Cet imaginaire du seuil se traduit notamment par la dilution (lourde d'implications) des frontières entre l'oral et l'écrit, par une extraordinaire confluence culturelle (héritage celte, gréco-romain, traditions populaires, etc.) en permanente tension avec le logos chrétien dominant, et par la quête et la revendication d'une identité poétique singulière. Celle-ci, en se déclinant désormais dans cette maternelle à la fois puissante, enivrante et fragile qu'est le roman, langue du désir et de la fiction promue au statut de l'écrit, cherche à s'affranchir des modèles poétiques et linguistiques issues de la latinité, c'est-à-dire, d'une langue et d'une cultures autres dont l'auctoritas (scripturaire et symbolique) tout à tour glorifiée, mise à distance ou ensevelie est l'emblème les enjeux complexes de cette relation de contiguité et de discontinuité, de semblance et de dissemblance, entre identité et altérité. Le choix de la chanson de geste est également significatif car l'épopée médiévale - genre qui problématise plus que tout autre une identité collective dont les fondements (idéologiques, culturelles et territoriaux) sont sans cesse menacés par une altérité exogène ${ }^{11}$ ou endogène ${ }^{12}$ - déploie un imaginaire poétique qui met fréquemment en cause les frontières instables et poreuses entre le Même et la Différence, l'Ici et l'Ailleurs, le Mythe et l'Histoire, l'impensé symbolique et la prévisibilité sémiosémantique de l'ethos guerrier.

Pourquoi le masque finalement ? Tout d'abord parce sa présence semble d'emblée contredire l'épistémè épique ${ }^{13}$. Mais aussi parce que le masque, loin de se résorber dans l'occultation, est dévisagement, c'està-dire processus dynamique en perpétuelle tension de dédoublement et de reconfiguration identitaire. Bien qu'il puisse en être à la conséquence logique, le masque ne relève ainsi pas forcément (ou uniquement) d'une structure oppositionnelle apparentée au schème diairrétique (être vs paraître, vérité vs mensonge ou simulacre, etc.) débouchant le plus souvent sur un rapport d'ordre dialectique qui implique, à chaque fois, une nouvelle synthèse identitaire. Le masque fonctionne, en somme, à l'image de cette particule magique de la langue - la conjonction de subordination « comme »-, emblème de la frontière que l'on transpose sans l'abolir permettant un élargissement sémantique et identitaire, une intégration des caractéristiques imaginaires propres à chacun des domaines comparés sans que l'on sombre néanmoins dans l'indifférenciation ou l'éclatement confusionnel de la métaphore. Le masque peut ainsi devenir l'emblème de ce Soi-même ricœurien qui se rêve comme un Autre ${ }^{14}$.

Mais l'utilisation du masque par le héros épique ne va pas de soi. Nul n'ignore en effet que le masque, surtout dans une civilisation théocentrique comme celle du Moyen Âge, a toujours quelque chose de 
sulfureux et de diabolique dans la mesure où il met en cause la perfection et l'intégrité de la plastica Dei qui préside à la Création ${ }^{15}$, où il brise la relation analogique, basée sur la (res)semblance, entre l'Ici et l'Ailleurs, le microcosme et le macrocosme, et introduit, de ce fait, une faille (aussi bien ontologique que métaphysique et herméneutique) entre le signe (langage ou realia) et le signifié au sein d'un univers essentiellement symbolique. Il est certes des masques plus menaçants que d'autres, le déguisement du héros dans la chanson de geste (où le recours à la ruse comme stratégie militaire est légitimé en tant que moyen indispensable à la restauration de l'ordre culturel et idéologique de la Chrétienté) ainsi que l'effacement identitaire aux contours initiatiques $\mathrm{du}$ chevalier arthurien ne pouvant être comparés aux métamorphoses quasi gnostiques $^{16}$ d'un personnage comme Merlin. Les récits épiques ne cessent néanmoins de nous rappeler que le brouillage engendré par le masque et par la non-reconnaissance qu'il introduit véhicule toujours le spectre de l'oubli de soi et de la mort.

D'un point de vue strictement narratif et rhétorique, nous pouvons ainsi établir que l'émergence du déguisement au cœur d'un personnage qui devrait incarner l'immutabilité et la permanence (alors que, selon la topique de l'épopée, c'est toujours l'Autre - paien, sarrasin ou traitre - qui manifeste une imprévisibilité identitaire menaçant la société et le logos chrétiens) inverse les rapports, et inscrit au sein de la chanson de geste la dimension fictionnelle (et romanesque) de la métaphore ${ }^{17}$. Celle-ci, à son tour, émiette un processus de signification fondé essentiellement sur une pratique de la contiguïté (métonymique) régissant aussi bien la dispositio des récits que le portrait des héros sur fond d'antithèses structurantes (jeux d'opposition binaires). Or, cette inflexion implique à son tour une mutation (aux contours civilisationnels) dans les rapports à cet Autre qui assiège et usurpe l'espace identitaire et sémiologique de la Chrétienté en y introduisant une impropriété qui trouble la rectitude grammaticale et syntaxique du monde dont le discours épique se veut la manifestation collective. Les topoï qui signalent et (d)énoncent cette altérité sont bien connus et fonctionnent comme un réservoir de stéréotypes culturels et imaginaires où la peur anxiogène face à l'Autre côtoie une inquiétude archaïque face à la Différence, les caractéristiques attribuées au champion sarrasin (monstre aux yeux rouges, au corps hybride ou bifide qui se termine par une queue, aux ongles affilées, au ventre enflé ${ }^{18}$, l'échine courbe, créature idolâtre ${ }^{19}$ d'un Dieu ivre ${ }^{20}$ et stérile ${ }^{21}$ ) nétant souvent qu'une projection inversée des fantasmes (politiques, sociaux, eschatologiques et économiques) qui menacent une civilisation féodale en pleine mutation ${ }^{22}$. En effet, la monstruosité (qui s'inscrit souvent dans un imaginaire onomastique lui-même très révélateur ${ }^{23}$ ) ne désigne (ou ne dé-signe) pas seulement cet Autre exogène à la société féodal (le Sarrasin) que les textes se plaisent à déshumaniser à outrance ${ }^{24}$. Que l'on songe au corps grotesque d'Hersent dans une chanson de geste comme Aiol, la femme du boucher d'Orléans, dont la nature hideuse incarne à la fois un dysfonctionnement du langage (parole déréglée et discourtoise) et une moralité perverse qui se manifeste à travers la richesse obtenue illicitement grâce à la pratique diabolique de l'usure (forme particulièrement insidieuse de l'échange économique 
qui menace, plus que toute autre, les structures idéologiques de la féodalité ancrées dans l'imaginaire oblatif). La satanisation de l'Autre (juif, sarrasin, avare, usurier ou hérétique) dans la chanson de geste se traduit invariablement par une hypertrophie et une sur-codification du corps qui devient un signe délirant, parasitaire, incontrôlable, polysémique et excessif qui menace l'ordre social, culturel et idéologique, ainsi que la stabilité du Sens. Dans la mesure où il rend perméables les frontières entre mondes et catégories physiques et métaphysiques distinctes (humain, divin, animal, végétal), le corps monstrueux constitue, dans son infini plasticité et son hétérogénéité radicale, un défi à la représentation et la connaissance à travers lequel l'Autre devient figure et nom de l'impensée ou de l'impensable qui ne cesse à la fois de mettre en question et de conforter les limites de notre identité humaine ${ }^{25}$.

\section{L'Autre : identité fictionnelle et fiction identitaire}

$\mathrm{D}$ 'où le fait que la topique de la rencontre avec l'Autre, modalisée par un masque qui ne colle jamais parfaitement au corps du héros épique, soit si souvent nuancée (comme nous le verrons plus loin) ou exorcisée par l'humour, le sérieux qui soi-disant caractérise l'épopée se déplaçant alors vers le registre parodique ou burlesque ${ }^{26}$ et l'excès sémantique consubstantiel au rire devenant expression singulière d'un manque toujours à combler ${ }^{27}$.

Le recours au déguisement serait-il alors une façon paradoxale de colmater une faille (aussi bien intérieure qu'extérieure au sujet), d'estomper la différence, de renouer avec la Forme Première des signes et du sens à travers l'expérience de la dissemblance $^{28}$ où le corps acquiert le statut de support métaphorique de l'identité ? Quoiqu'il en soit, il est d'abord et surtout constat de la relative inadéquation d'un ethos épique uniquement ancré dans la violence meurtrière qui fait si souvent de la chanson de geste primitive une " poétique du génocide joyeux $»^{29}$ engendrant une " hémorragie de l'écriture $»^{30}$ qui transforme l'épopée en une plaie béante d'où s'écoule un récit toujours à venir, fruit d'un sang (et d'un sens) qu'il faut sans cesse étancher, purifier et venger. Le discours de la violence traduit, en effet, l'échec de toute communication avec l'Autre, expression exacerbée et hyperbolique de deux récits identitaires en conflit qui ne parviennent jamais à (se) transformer (l'un) l'autre et à produire un sens nouveau : d'où le fait que la rhétorique de la violence s'exprime souvent à travers un style formulaire au sein duquel les cris de guerre scandent le récit à la manière d'une litanie incantatoire appelant à un sacrifice rédempteur aux contour eschatologiques :

«Monjoie! » escrient par merveilleus esforz;

«J a i avra des navrez et des morz! » [...]

Tote la terre est couverte de sanc (Le Charroi de Nîmes, v. 1399-1400 ; 1429).

En se présentant, du point de vue narratif, comme une stratégie pour accéder à l'espace interdit de l'Autre (le double sarra$\sin )^{31}$, le masque traduit, au contraire, une tentative de (r)établir la communication, ce qui implique un profond basculement sémiologique et symbolique passant aussi 
bien par une réécriture du corps que par une réinvention de la langue ${ }^{32}$. La notion ricœurienne $d$ ' " identité narrative $"^{33}-$ comme espace dynamique de médiation, de reconfiguration et de dialectisation de l'expérience et du sujet (aux implications tant sur le plan ontologique qu'herméneutique) - s'avère être ici particulièrement importante et fonctionnelle ${ }^{34}$. En effet, le déguisement sarrasin préserve l'identité et la cohérence poétiques du héros et assure sa permanence substantive dans le temps (dimension de la mêmeté préservée par certains attributs immutables, comme la bosse sur le nez chez Guillaume d'Orange) tout en permettant au sujet de se découvrir et concevoir lui-même, dans le temps de l'ipséité, comme un Autre ${ }^{35}$.

Les réflexions qui suivent s'attarderont surtout à scruter cette dimension transfigurante et transfiguratrice de la rencontre avec cet Autre par excellence qu'est le paien, figure poétique, culturel et langagière à travers laquelle la chanson de geste finit par s'interroger, de l'autre côté du miroir, sur ses propres fondements civilisationnels, idéologiques et littéraires. Ce dernier aspect est particulièrement important, car il montre que le masque - à moins qu'il soit immédiatement voué à l'échec ${ }^{36}$ - n'est pas uniquement un stratagème militaire ou un simple motif au service d'un programme textuel précis, impliquant le plus souvent une véritable reconfiguration narrative de l'identité et de l'univers à travers laquelle le héros découvre qu' « il est toujours possible de tramer de sa propre vie des intrigues différentes, voire opposées ${ }^{37}$. Comme dans la métaphore ou dans le rituel de l'hospitalité, la rencontre avec l'Autre sous l'égide (ou à travers la médiation) du masque suppose ainsi la création d'une zone de confluence (ou de convergence) au creux de laquelle, ne serait-ce que durant un instant, les frontières culturelles et identitaires entre Chrétiens et Paiens, le Même et la Différence, s'estompent, s'annulent ou s'inversent. Or, c'est précisément ce glissement qui accompagne la complexification de l'identité narrative du héros épique qui fait de la rencontre avec l'Autre l'occasion privilégiée d'une révélation quasi épiphanique de la vérité du sujet et du monde.

Amplement connu et abondamment commenté, l'exemple du Charroi de Nîmes (une des rares chansons du Cycle de Guillaume d'Orange de la première moitié du $\mathrm{XII}^{\mathrm{e}}$ siècle qui nous est parvenue) est à cet égard très éloquent. Oublié par le roi Louis lors du partage des fiefs alors qu'il se divertissait à chasser à l'arc dans la forêt, Guillaume « au courbe nez ${ }^{38}$ se révolte contre le pouvoir défaillant de ce souverain ingrat qui lui doit pourtant son royaume, menaçant même de lui « abatre la corone del chief » (v. 435). Renonçant à tous les dons que Louis lui offre pour le (ré)compenser, il se lance alors dans l'expédition téméraire de reconquérir Nîmes gouvernée par les rois païens (frères l'un de l'autre) Harpin et Otran. À proximité de Saint-Gilles, les guerriers croisent un singulier convoi mené par un sarrasin qui gagne pauvrement sa vie en achetant et en vendant du $\operatorname{sel}^{39}$. Monté sur le char, ses trois enfants rient et jouent aux billes (v. 873-885). Cet épisode, apparemment anodin, incite à plusieurs remarques. La première concernant tout d'abord le personnage (maintenu dans l'anonymat) qui fait l'objet de cette singulière rencontre et qui incarne l'Autre dans sa double nature exogène (il s'agit d'un sarrasin) et endogène (il incarne une vision du monde ancrée dans la transaction 
monétaire qui se heurte à l'imaginaire aristocratique et à sa conception de la valeur).

La deuxième a rapport à l'espace dans lequel se déroule la rencontre que le texte situe dans la géographie du territoire occupé par les païens, soulignant clairement la frontière qui sépare le monde de l'identité et l'univers de l'altérité et les risques que cette transposition implique :

«Baron, » dist il [Guillaume], « envers moi entendez.

Vez ci les marches de la gent criminel; D'or en avant ne savroiz tant aller

Que truissiez home qui de mere soit nez

Que tuit ne soient Sarrasin et Escler » (v. 849-853).

Cette frontière physique et symbolique est doublée par une autre frontière qui, durant des millénaires de civilisations diverses, «n'a cessé dêtre le réceptacle d'une dense et féconde imbrication de peuples et de cultures $»^{40}:$ la Méditerranée ${ }^{41}$. Tout comme Montpellier, Narbonne, Arles, Marseille ou Barcelone, Saint-Gilles et Nîmes figurent comme autant de toponymes qui imprègnent l'imaginaire épique aux $\mathrm{XII}^{\mathrm{e}}$ et $\mathrm{XIII}{ }^{\mathrm{e}}$ siècles et qui semblent suggérer une étroite symbiose géographique et symbolique entre le bassin méditerranéen et la chanson de geste française. Que l'on se souvienne, dans la Chanson de Roland (manuscrit d'Oxford, laisses 189190), de la traversée de la Méditerranée par la grande flotte de guerre de l'émir Baligant : des sarrasins venus de quarante royaumes se rassemblent à Alexandrie, traversent la Méditerranée et remontent l'Ebre jusqu'à Saragosse pour venir en aide au roi Marsile et annihiler les troupes de Charlemagne.
Inscrite aux origines même de l'écriture épique, la Méditerranée se dessine comme un espace médiateur extrêmement ambigu. Frontière fluide et instable entre le monde chrétien et le vaste univers de la païenneté, le monde connu, parfaitement circonscrit et ordonné, et l'espace indifférencié et menaçant de l'Autre, entre l'univers réconfortant du symbole et l'éclat séduisant des signes et des simulacres qui miroitent à travers les richesses et les pouvoirs secrets, séduisants ou inquiétants attribués au monde paien ${ }^{42}$, la Méditerranée représente un espace d'échanges linguistiques, commerciaux, religieux, artistiques et identitaires. Elle se dessine, en somme, comme un espace de transferts et d'hybridations multiples ${ }^{43}$ qui - bien que nétant jamais exempt de tensions, de rivalités ou d'antagonismes irréconciliables entre stéréotypes culturels et idéologiques qui peuvent tourner au conflit - déplacent sans cesse les frontières culturelles, bouleversent l'ordre du monde et infléchissent la nature, le statut et les enjeux (idéologiques, poétique et symbolique) de l'univers épique. Comme zone perméable favorisant la mobilité, le passage, la dynamique de la transmission (qui transforme aussi bien l'émetteur que le récepteur) et de la confluence, la Méditerranée devient le lieu où tout peut basculer.

Troisième remarque : d'après les indications du marchand sarrasin, Nîmes semble tout d'abord surgir comme modèle d'un bon gouvernement vu que le païen finit par être exempté de taxes à cause de sa condition sociale précaire et du fait que le prix des denrées essentielles (comme le pain) y est moitié moins cher que dans d'autres villes ${ }^{44}$. Cet équilibre, bien que relatif et relativisé par le païen, serait-il l'envers de l'ingratitude de Louis, parangon 
de la Chrétienté, l'Autre devenant modèle exemplaire (ou idéalisé), bien que discret, de la souveraineté carolingienne ? Notons ensuite que parler la langue de l'autre (comme le fait si habilement Guillaume ${ }^{45}$ ) ne signifie pas forcément parler dans la langue de l'autre, la communication étant, comme nous le savons, davantage qu'un simple transfert sémantique et syntaxique d'un code linguistique vers un autre, vu qu'elle déclenche toujours un processus cognitif impliquant nécessairement une vision du monde (un imaginaire) qui est propre au sujet de l'énoncé et à la culture dont il est $\mathrm{imbu}^{46}$. D'où l'équivoque lorsque Guillaume interroge le païen sur les « estres » de la ville (v. 908), ce dernier centrant sa réponse sur les conditions économiques (prix du pain, gabelle, etc.), alors que le héros chrétien était surtout soucieux de connaitre les dispositions militaires et défensives de Nîmes. Constatons finalement que Guillaume est le seul à prendre la défense du pauvre commerçant contre l'hostilité manifeste de ses compagnons ("Baron, lessié ester », v. 900) comme s'il voyait en lui un double au miroir. Et pour cause, car le « réalisme » sous-jacent à cette rencontre avec l'Autre (pur dispositif mimétique propre à une écriture fictionnelle qui se légitime en utilisant les ressources rhétoriques du discours de l'histoire ${ }^{47}$ ) acquiert une profondeur symbolique qui transperce la surface idéologique du récit ${ }^{48}$. Elle érige, en effet, la figure du pauvre marchand de sel (matière qui renvoie notamment - par sa valeur aussi bien alimentaire que rituel liée à la purification et au sacrifice - au topos biblique du « sel de la terre », Matthieu, 5, 13) accompagné de ses enfants (autre motif cher aux Évangiles) jouant aux billes (figuration analogique des sphères célestes représentant le cosmos et la souveraineté ?) en messager providentiel d'une identité narrative à reconstruire ou à réinventer qui motive et oriente symboliquement les motifs de la ruse ("voidie", v. 919) et du masque. Notons au passage que le symbolisme (toujours polyvalent et réversible) lié au sel se complexifie considérablement si nous croisons d'autres sources médiévales au-delà des Écritures : élément transformateur par excellence (d'où sa présence dans le rite baptismal, mais également dans les procédés alchimiques ${ }^{49}$ ou dans les procès contre la sorcellerie), le sel est également réputé, suivant une tradition qui remonte au moins jusqu'à Pline l'Ancien (Histoire naturelle, XIXX, 82), pour ses propriétés chimiques et médicinales. Dans ses Étymologies (XVI, 2, 3-6) Isidore de Séville souligne que sa désignation ( $(s a)$ peut aussi bien dériver du fait que le sel, élément igné, saute (exsilire) lorsqu'il rentre en contact avec l'eau, que de sa double nature maritime (salum, la mer) et solaire (sol) qui rend les corps plus vigoureux (salus, la santé). Bien plus tard, Hildegarde de Bingen réitère, dans Le Livre des subtilités des créatures divines ${ }^{50}$ (Liber simplicis medicinae), les vertus médicinales du sel déclinée d'après les catégories aristotéliciennes et la théorie des humeurs remontant à Hippocrate et Galien (chaud/froid, sec/humide). "Très chaud et quelque peu humide » (p. 163), le sel, consommé avec modération, évite que le corps ne devienne trop tiède ou, au contraire, trop aride, le sel en excès pouvant notamment dessécher les poumons. Il est ainsi, conclue Hildegarde de Bingen, «le sang et la fleur des eaux [...] [qui] donne des forces à celui qui en use avec mesure ", mais déclenche « une sorte d'inondation et de tempête » à celui qui en use sans mesure 
(p.163-164). Au début du XIII' ${ }^{\mathrm{e}}$ siècle (mais transmettant récits, traditions, croyances et observations sans doute bien plus anciens), Gervais de Tilbury raconte, dans ses Otia imperalia ${ }^{51}$ (divertissements pour les gens de la cour), une réalité digne d'émerveillement concernant justement le sel produit à proximité d'Arles dans une région marécageuse que Lucain nommait « les rivages de Stoechades » :

Tout comme l'eau froide dans la rigueur de l'hiver, se transforme en glace à cause du froid qui la fige, de même l'eau salée, qui est chaude et sèche, s'épaissit en formant du sel à cause de la chaleur qui la fige, durant le torride mois d'août : ainsi, ce que fait le froid en la durcissant, la chaleur le fait en figeant l'eau en sel, par assèchement (2, p. 23).

Plus qu'une simple marchandise, le sel apparait ainsi comme un élément qui relie l'eau, le feu et la terre, pouvant transformer chaque structure en son contraire ('eau qui se pétrifie, par exemple). Outre ses connotations bibliques, il assume ainsi, dans cette séquence narrative, une importante dimension médiatrice et transformatrice, voir prophétique, qui fait miroiter l'identité plurielle et paradoxale de ce héros à la nature à la fois solaire et chtonienne, où l'bybris guerrière côtoie l'art de la mètis (la ruse, la métamorphose, l'anticipation sur les évènements, i.e., une certaine maîtrise du temps, la plasticité verbale, etc.) à travers laquelle Guillaume renoue avec ses attributs mythiques cachés sous le voile de la persona épique.

Quatrième remarque : inspirés par Garnier, qui « d'engignement sot tote la mestrie " (v. 920), les chrétiens acquièrent alors grande quantité de charrettes et de bœufs et se déguisent tous en marchands. L'affaire ne va pas de soi. Sous le rire amusé de ses compagnons, Bernard (le neveu de Guillaume qui « ne fue mie del mestier doctriné ", v. 1003), s'embourbe misérablement, signe d'une société chevaleresque qui se sent mal à l'aise à jouer les laboratores. Mais l'enjeu est-il ici simplement d'ordre idéologique ? Que dénonce cet excès de sens sous-jacent au rire ? L'épisode n'est pas sans rappeler la fameuse séquence, aux allures de foire et de mascarade, du Mal Pas dans le Tristan de Béroul, cet espace marécageux où tous s'emmêlent les pieds (et la langue), où s'effacent totalement les signes distinctifs de la hiérarchie sociale et du pouvoir, où la superbia chevaleresque tombe soudain dans la boue, et où la fonction référentielle de la parole se dissout entièrement dans la dubia locutio du discours de Tristan et d'Iseut qui (dis)simulent la vérité sous les traits (fictionnels, métaphoriques) du masque physique et verbal. Dans les deux cas, les récits basculent dans l'univers carnavalesque qui inverse et renverse l'Ordre (de la société, du langage, des signes, du cosmos) et brise la surface idéologique des poèmes d'où émerge alors «le chant profond $»^{52}$ du mythe ${ }^{53}$. Cinquième remarque : caché dans les tonneaux les guerriers pénètrent dans la ville, le dédoublement identitaire étant renforcée par le glissement métaphorique du discours marchand dominé lui aussi par la dubia locutio qui érige le mensonge fictionnel en vérité narrative (ou vice-versa) ${ }^{54}$. Constatons encore qu'à l'opposé des produits vantés par ses compagnons (tissus somptueux, armes étincelantes, etc. ${ }^{55}$ ), la parure de Guillaume semble prolonger celle du 
pauvre négociant de sel. Monté sur une " jument molt foible ", vêtu d'une modeste tunique de bure et exhibant d'étranges souliers de bœuf, étriers et éperons usés par le temps (v. 1036-1046), cet alter Christus a apparemment gommé de son corps tout signe de la superbia et de l'bybris chevaleresques et guerrières. L'ampleur narrative de ce masque identitaire est elle-même considérable : neuf laisses et près de 200 vers dans un poème extrêmement court (près de 1486 vers). Lidentification à l'Autre (dé)structurant (le Sarrasin marchand de sel) se poursuit et s'amplifie avec la référence aux dix-huit fils du héros (une prolifération généalogique qui caractérise généralement les lignages païens ${ }^{56}$ ), les deux plus âgés (rôles joués par Guïelin et Bertrand), désignés par les noms de Bègues et de Sorant (v. 1124-1128), pouvant préfigurer la transformation imminente de Guillaume. En effet, le bégaiement inscrit au cœur du signifiant nominal du premier, signe de l'immensité de la parole divine qui trouble et désarticule le langage humain, n'est-il pas un des traits distinctifs de l'élu, du prophète ? Que l'on songe, par exemple, à Moïse le bègue, qui propose alors d'envoyer son frère Aaron pour parler au nom de Dieu (Ex. 3), ou bien à Jérémie $(J r .20$, 9) ou encore à $A$ mos $(A m .3,8)^{57}$. Quant à la forme sorant, ne fait-elle pas miroiter l'adjectif sore désignant une couleur à la fois brillante et instable (la couleur fauve, par exemple) qui s'applique notamment au plumage d'un oiseau qui n'a pas encore mué ? À la fois divine (ou sacrée) et fictionnelle, la descendance de Guillaume ne serait donc autre que la projection de la mutation initiatique du héros qui culmine avec l'adoption d'un nouveau et énigmatique nom (im)propre (Tiacre) et la réinvention, aux contours nettement mythiques, comme nous le verrons plus loin, de sa trajectoire identitaire et narrative. Aussi, d'Angleterre jusqu'en Allemagne, en passant par l'Espagne, la Lombardie, la Hongrie, la Roumanie ou les divers royaumes de France (v. 1189-1202), l'espace maîtrisé par l'intense activité commerciale du héros se confond-il avec l'univers balisé (et éternellement menacé) de l'empire carolingien (que Fièrebrace n'a de cesse de reconquérir par l'activité guerrière) tout en signalant le rôle éminemment civilisateur que le Moyen Âge, surtout à partir du XII ${ }^{e}$ siècle, conferre au marchant ${ }^{58}$. Et lorsque sa véritable identité est sur le point d'être révélée par Otran qui reconnait «la boce sor le nes» (v. 1202), Guillaume surenchérit sur le masque en récrivant l'histoire de ses origines :

"Quant ge fui juenes, meschins et bachelers,

Si deving lerres merveilleus por embler Et engingnierres; onques ne vi mon per Copoiee borses et gueilles bien fermez;

Si m'en repristrent li juenes bacheler Et marcheant cui ge avoie enblé;

A lor coteaus me coperent le nes, Puis me lessierent aler a sauveté; Si conmençai cest mestier que veez.

La merci Deu, tant en a conquesté

Conme a voz eulz par ici esgardez.» (v. 1243-1244)

Indépendamment de l'interprétation (toujours incertaine) qu'on puisse lui attribuer, ce récit (véritable invention, au sens rhétorique du terme) opère un remarquable transfert métaphorique du passé : héros sans père (et sans pair, d'après une 
homophonie bien connue du roman arthurien), éternel bachelier aspirant à trouver un espace (sans cesse dénié par le roi Louis) où il puisse finalement ancrer son identité (ce qu'il fera grâce à la double conquête d'Orable, la belle sarrasine qui deviendra sa femme Guiborc, et de la ville d'Orange), Guillaume/Tiacre s'imagine sous les traits d'un habile larron (un usurpateur de la proprietas d'autrui, condition à laquelle l'a condamné l'ingratitude du souverain) dont l'identité mutilée (l'amputation nasale ${ }^{59}$ ) est à l'origine d'une mutation sociale et identitaire. D'autre part, en revêtant successivement le masque du voleur et $\mathrm{du}$ marchand (la frontière entre ces deux figures étant parfois très ténue dans la mentalité féodale et ecclésiastique), Guillaume légitime du même coup la rhétorique de la ruse (l'engin), de la déviance, dont il use pour conquérir Nîmes, sa persona étant dès lors davantage façonnée selon les modèles romanesques de Renart ou de Tristan ou selon le modèle mythique de Loki dans la tradition scandinave (incarnation de l'ingéniosité, de la ruse et de l'intelligence créative $)^{60}$ que d'après le paradigme épique d'un Roland. Au cour de cette identité mytho-poétique plurielle (l'astuce et éloquence, mensonge et commerce, etc.) qui émerge de la rencontre fulgurante avec l'Autre et du transfert identitaire qui s'ensuit, Guillaume se révèle également sous le visage d'Hermès/Mercure que le Moyen Âge connaissait justement sous les traits ambivalents de l'éloquence divine et poétique liée au spectre menaçant de la fraude verbale et de la contrefaçon ${ }^{61}$.

La scène suivante qui narre la révolte de Guillaume après qu'un cuisinier sarrasin (sur les ordres du roi Harpin) ait tué ses deux bœufs ${ }^{62}$ (scène durant laquelle le héros déclinera son nom propre et son lignage) est particulièrement révélatrice, suggérant plusieurs aspects cruciaux de la rencontre avec l'Autre modalisée (ou médiatisée) par le masque et de l'épiphanie identitaire et symbolique qui l'accompagne. Certes, face à l'inquiétante réussite du déguisement, Guillaume craint que celui-ci ne finisse par dévorer son identité (aussi bien textuelle que lignagère), s'empressant bientôt de restaurer la frontière entre le sujet et l'Autre et plaçant le déguisement sous le signe de l'inversion pure (" Cist Sarrazins m'a fet ore contraire », v. 1341). Cependant, la façon dont il apparaît au regard d'autrui témoigne que le retrait du masque n'est pas simple retour au Même, l'identité narrative du héros devenant plus riche, ambiguë et complexe à la suite de l'expérience fictionnelle de l'altérité $^{63}$. Guillaume n'est plus uniquement « Guillelmes Fierebrace,/ Filz Aymeri de Nerbonne le sage » (v. 1339-1340), mais un être poétiquement et symboliquement multiple. Remarquons d'ailleurs que, lors du dialogue qu'il entretient avec le héros, ce qui intrigue le plus le roi Harpin, ce qui désigne à ses yeux l'étrangeté menaçante du masque, ce n'est ni vraiment le visage ni la langue parlée par Guillaume/Tiacre, mais la parure surprenante qu'il exhibe :

Li rois Harpins li a dit par contraire : «Diva, vilians, Mahomez mal te face! Por quoi as or si granz sollers de vache, Et ta gonele et tes conroiz si gaste? Bien semble hon qui ja bien ne se face » (v. 1327-1331).

Dans ce monde à l'envers où Harpin joue subitement au Petit Chaperon Rouge laissant à Guillaume le rôle du loup 
dévorateur, la référence aux habits usés (l'adjectif gaste évoquant la dévastation, la " terre gaste » et stérile du roman arthurien) et surtout la référence insistante aux « souliers de vache " (reprise au v. 1336) font-ils simplement de Guillaume le héros " du dénuement total, d'une tabula rasa, promesse de renouveau et de rédemption ${ }^{64}$ ? Ou fonctionneraient-ils comme des marqueurs symboliques dénonçant la présence vestigiale et fragmentaire d'un (ou de plusieurs) récit(s) mythique(s) qui fonde(nt) l'identité profonde du héros ? On ne saurait en effet ignorer la prégnance, au cœur de toute cette séquence qui raconte la prise de Nîmes, d'une mythologie cohérente structurée autour du motif du bœuf (le char du commerçant sarrasin qui s'embourbe, les deux bœufs tués par le cuisinier, les souliers de vache, etc.). Partant de l'ambiguité sous-jacente au terme « sollers " (les souliers de vache qui font également résonner l'adjectif latin signifiant " habile", « rusé »), Alain Corbellari conclut :

[...] 'habile aux bœufs', Guillaume rejoint ainsi des personnages bien connus de la littérature médiévale, tel le farceur Unibos, héros d'un texte latin du XI ${ }^{e}$ siècle, qui fonde toutes ses mystifications sur la vente de la peau de son bœuf, ou Boivin de Provins, dans le fabliau homonyme, qui fait miroiter l'argent fantôme d'une prétendue vente de deux bœufs, ou peutêtre Trubert $[\ldots]^{65}$.

Mais, au-delà - ou en-deçà - de cette intertextualité strictement poétique, le poème ne pourrait-il pas être également traversé par un puissant intertexte mythique? La peau de vache (bursa en grec) ou le sacrifice de la peau de vache, ne s'inscrivent-ils pas, en effet, au cœur du muthos lié symboliquement à la fondation de la cité, notamment dans les récits antiques qui entourent la fondation de Carthage que John Scheid et Jesper Svenbro ont minutieusement étudié ${ }^{66}$ ? Or, que nous rapportent les épopées médiévales centrées sur le thème de la reconquête sinon des mythes de fondation ou de refondation historicisés ? Nul n'ignore non plus, à la suite des probantes études de Georges Dumézil, que dans de nombreuses épopées reflétant l'idéologie indo-européenne (la Mahābhärata, par exemple), la souveraineté incarne à travers plusieurs qualités héroïques dont l'habileté dans le soin des vaches et des chevaux ${ }^{67}$. Certains récits commémorant le duel du dieu guerrier Indra et du héros épique Arjuna contre le soleil sont également révélateurs :

[...] de même qu'Indra, dans ce duel, est vainqueur parce qu'il " détache " ou « enfonce » une des roues du char solaire, de même Arjuna, fils d'Indra, au VIII ${ }^{e}$ livre du Mahābhārata, ne vient à bout de Karna, fils du soleil, que parce qu'une des roues du char de celui-ci s'enfonce miraculeusement dans le sol. ${ }^{68}$

Bien que très incomplet et approximatif, ce bref dossier mythologique nous permet néanmoins de lancer de nouvelles hypothèses concernant l'échange identitaire qui préside à l'épisode du charroi. Sous la toile du mythe (re)fondateur, l'histoire du char qui s'enfonce dans la terre est plus qu'une simple stratégie militaire ou un simple avatar du Cheval de Troie, dévoilant probablement une séquence mythique 
qui raconterait le combat cosmologique contre le Temps dont l'enjeu est à la fois la restauration de L'Ordre du Monde (un Ordre troublé par la présence de l'Autre) et la conquête, par Guillaume et ses compagnons, de la Souveraineté symbolique et idéologique $^{69}$.

\section{Parler (dans) la langue de l'Autre ou la controverse poétique}

$\mathrm{D}$ 'autres poèmes du même Cycle mettent en évidence cette familiarité, stratégiquement pratique il est vrai, mais non moins inquiétante, de Guillaume avec l'univers du déguisement tout en soulignant son statut initiatique ${ }^{70}$. C'est notamment le cas dans La Chanson de Guillaume et Aliscans. Ces deux chansons de geste se déroulent dans une atmosphère aux contours eschatologiques d'une imminente désagrégation de la Chrétienté carolingienne à la suite de la bataille d'Archamp (parcourue par le spectre de Roncevaux) et dénoncent les dangers (exorcisés par Guillaume dans Le Charroi) d'un masque collant si parfaitement au corps qu'il finit par exclure (ou à expulser) momentanément le héros d'un récit identitaire dans lequel il ne se reconnait plus. En effet, après avoir perdu ses valeureux compagnons, Guillaume parvient à traverser l'espace saturé par la présence de l'Autre et à rejoindre Orange (défendue par Guiborc) déguisé en guerrier sarrasin («Paenes armes li pendent al costez », v. 2232 ${ }^{71}$ ). Face à l'effacement de tout signe distinctif de l'identité, devenu entièrement Autre que soi-même, l'entrée dans la ville lui est successivement refusée et par le portier et par sa propre femme qui lui attribue les qualités généralement accordées aux païens, maîtres es arts du mensonge ; un art que rien ne distingue, en outre, du simulacre fictionnel ou de l'invention poétique $^{72}$ :

[...] « Vus nus mentez!

Culvert paien, mult savez de cuntrover; Par tels enseignes ça enz nen enterez » (v. 2240-42).

L'utilisation de forme verbale controver est, dans ce contexte, extrêmement révélatrice. En effet, si l'on tient compte que l'inventio poétique consiste à (re)trouver (trover, troveure, trovement en ancien français) et à restaurer l'intégrité, la cohérence et l'homogénéité d'une ancestrale parole perdue ou ensevelie, oubliée, déformée ou gardée dans le plus profond des secrets ${ }^{73}$, son double négatif, la fable corrompue et mensongère car transmise par des jongleurs sans scrupules, se place, quant à elle, invariablement sous le signe de la controvure où la mimésis fictionnelle devient image de la fraude et de la contrefaçon poétique, c'està-dire simulacre trompeur et subversif de la vérité aux contours lucifériens. Incarnant l'infinie plasticité des formes et du langage, voici que Guillaume devient, à travers l'expérience fictionnelle de l'altérité, le double du jongleur et du poète.

En différant sans cesse, au seuil de la mort ( La moer u vive, la m'estoet aller ", v. 2273), le temps de la révélation épiphanique de l'identité, Guiborc prétend bien entendu mettre une dernière fois à l'épreuve la persona héroïque de son mari. Guillaume ne s'y trompe d'ailleurs pas lorsqu'il dénonce la nature initiatique de l'exorbitante exigence formulée par sa femme ("Tut veirement me volt espermenter », v. 2272) qui le conduit à assumer le masque jusqu'au bout et à tuer une bonne 
quinzaine de sarrasins qui le prennent pour leur seigneur. Conjurant la ruse en la réorientant sur une sémiologie toute épique de la violence, Guillaume montre ainsi sa valeur et son appartenance incontestable à l'ordre de la Chrétienté et à l'ethos épique. Il pourra alors ôter le masque, exhiber le signe tangible de son identité (la bosse sur le nez : v. 2310) et franchir définitivement les murs d'Orange.

Quelques années plus tard, la chanson de geste Aliscans procède à une remarquable amplificatio de cette séquence surenchérissant toutefois sur les enjeux et les implications (aussi bien identitaires qu'herméneutiques) du déguisement dont le texte se plaît à souligner la dimension langagière :

Et prist [Guillaume] les armes au paien desfaez $[\ldots]$.

Lors s'en torna,s'est a Dex commandez.

Sa langue torne, ses latins est müez:

Grezois parole, qu'il en fu doctrinez;

Sarrazinois resavoit il assez;

De toz langages ert bien enlatinez.

D'armes paienes iert mout bien adoubez;

Estrangement iert grande sa fiertez (v. 1715 ; 1728-1734).

Monté sur le destrier du puissant Aarofles qu'il vient de vaincre, voici que Guillaume, le guerrier épique devenue étrange(r) aux yeux même du narrateur, acquiert maintenant les traits du parfait lettré, incarnation d'une connaissance secrète du et sur le monde (transmise par les langues) que le Moyen Âge attribuait d'ailleurs volontiers, et pour cause, aux savants arabes ${ }^{74}$. Masque et multilinguisme font de la persona de Guillaume une identité extrêmement plastique qui se confond avec l'univers lui-même et brise le cadre poétique et idéologique strict de l'écriture épique, Fièrebrace renouant à nouveau, à travers ce don de la communication universelle, tant avec son double mythologique (Mercure/Hermès) qu'avec son double romanesque contemporain, Tristan. Dans le contexte d'une épopée marquée par l'épuisement (de la Chrétienté et de la topique littéraire qui l'énonce ${ }^{75}$ ), cette expérience langagière serait-elle promesse d'une nouvelle Pentecôte du récit ? Où creuserait-elle davantage encore l'atmosphère babélienne de la chanson de geste marquée par l'éternel descort des signes et du sens entre Chrétiens et Sarrasins ? L'ambigüité et la polysémie inhérentes au masque nous empêchent certes de trancher définitivement. Remarquons toutefois que dans l'épisode en question, ce n'est pas la parole qui trahit le héros, mais à nouveau sa parure, le déguisement sarrasin laissant cette fois-ci transparaître l'hermine blanche de son manteau et ses chausses couleur de sang (v. 1802-1810), expression d'une vérité de lêtre (les signes tangibles de l'identité nobiliaire) qui résiste à se laisser emprisonner/apprivoiser par/dans le masque physique de l'Autre, alors que le langage semble, au contraire, se définir comme la surface la plus sensible, plastique et perméable à l'action d'une mimesis trompeuse et, par conséquent, à l'expression du simulacre identitaire. C'est du moins ce que suggère la tirade de Guiborc dans l'une des variantes les plus intéressantes d'Aliscans ${ }^{76}$ face aux autres témoins de la tradition :

"Voir, dist Guiborc, tres bien oi au parler

Que mar devez Guillelmes ressembler, Car ainc nel pot nus Turs espoenter. 
Mes, par cel Deu que je doit aorer, N'i ferai porte deffermer Jusque je voie vostre chief dessarmer Et sor le nes la boce as elz mirer, Quar plusors homes se samblent de parler $»$ (v. 2048-2055).

Parler (dans) la langue de l'Autre ne serait donc, le plus souvent, qu'une façon détournée de parler (de) sa propre langue, support à la fois privilégié et fragile d'une identité narrative et poétique extrêmement instable et mouvante où les frontières entre soi-même et l'autre sont sans cesse basculées, inversées, gommées et redéfinies.

Intrinsèquement équivoque, à la fois fascinant et troublant à l'instar de cet Autre qu'il permet d'approcher, si le masque (qui commence par être expression d'une nouvelle sémiologie qui remplace le langage épique de la violence par l'art rhétorique du simulacre et de la ruse) et le dédoublement de l'identité qu'il permet conduisent à une révélation épiphanique et structurante de la vérité de l'être, il peut également provoquer la dispersion de l'identité et de la mémoire qui fondent et alimentent l'imaginaire collectif. Aussi, ce basculement et cette confluence identitaire et poétique ne peuvent-ils être, dans la chanson de geste, quéphémères épiphanies, ne parvenant jamais à effacer tensions, ruptures et rivalités qui continuent à faire de l'épistémè épique l'immense histoire d'un rapport conflictuel à l'Autre (quel qu'il soit d'ailleurs) où la communication est sans cesse interrompue et vouée à l'impasse. Perplexe face à l'extraordinaire réussite de son stratagème et surtout face à la nature extrêmement convaincante du récit autobiographique qu'il (ré)invente dans Le Charroi de Nîmes, Guillaume ne s'empresse-t-il pas, dès que loccasion se présente et que la fonction du dédoublement spéculaire est pleinement accomplie, à ôter un masque devenu particulièrement encombrant ? Il n'empêche que, lorsque l'épopée se met à parler mimétiquement (dans) la langue poétique et culturelle de l'Autre, les tensions se nuancent et se dialectisent considérablement, inaugurant un imaginaire de l'altérité bien plus riche et complexe qui brise et transcende la bipolarisation manichéenne des images, de la signification et des valeurs généralement attribuées à la chanson de geste, voire à la civilisation médiévale.

Dans l'enceinte irréelle de la fiction, nous ne laissons pas d'explorer de nouvelles manières d'évaluer actions et personnages. Les expériences de pensée que nous conduisons dans le grand laboratoire de l'imaginaire sont aussi des explorations menées dans le royaume du bien et du mal. Transvaluer, voire dévaluer, c'est encore évaluer. Le jugement moral n'est pas aboli, il est plutôt lui-même soumis aux variations imaginatives propres à la fiction ${ }^{77}$.

\section{Notes}

1. La Chanson de Guillaume, éd. bilingue F. Suard, Paris, Classiques Garnier, 1999.

2. P. Ricœur, Soi-même comme un autre, Paris, Seuil, 1990.

3. Voir, par exemple, la typologie des images proposée par J.-J. Wunenburger : Philosophie des images, Paris, PUF, 1997, p. 3-52 ; "Image et image primordiale », in D. Chauvin, A, Siganos et Ph. Walter (dir.), Questions de mythocritique. Dictionnaire, Paris, Imago, 2005, p. 194-197. 
4. Comme le souligne P. Ricœur (Soi-même comme un autre, p. 150), ce caractère polysémique «implique que l'Autre ne se réduise pas, comme on le tient trop facilement pour acquis, à l'altérité d'un Autrui ». 5. C'est-à-dire, cet «Autre, dépassant l'idée de l'Autre en moi » comme le voulait E. Lévinas (Totalité et infini, Paris, Le Livre de Poche, 1990, p. 43).

6. Question sans doute insurmontable, vu que toute construction symbolique, toute représentation, repose foncièrement sur une série de mouvements réflexifs, comme le rappelle Thierry Hentsch au sujet de l'indistinction entre mythe et histoire (que nous retrouvons au cœur de la chanson de geste), isomorphe de l'indistinction entre le même et l'Autre : "Placer côte à côte mythe et histoire, ici, c'est évoquer l'indistinction de la ligne qui les sépare. Or cette indistinction se retrouve à la frontière du même et de l'Autre. C'est dans le rapport de l'identité et de l'altérité que la dimension mythique de l'histoire apparait la plus prégnante. La question identitaire et la question des origines, pour toute société, baignent dans le même imaginaire. Voilà ce qui fait de l'histoire un miroir. Mais la réflexion est réversible : l'histoire à son tour s'inscrit dans le miroir de l'Autre » ("L'altérité dans l'imaginaire occidental : fonction manifeste, fonction occulte ", Revue d'Histoire de l'Amérique française, 79, 3, 2006, p. 347).

7. Notons que Platon aborde la question de l'altérité et de la Différence (to heteron) dans le Sophiste dans le cadre de la distinction parménidienne entre l'être et le non-être. Il pose alors que chaque chose n'est pas seulement ce qu'elle est, mais qu'elle est aussi différente de ce qu'elle n'est pas. L'Autre est ainsi cette extérieure qui permet de définir l'essence et la Forme de l'être et des choses. Or, c'est dans ce même traité qu'il définit le sophiste comme un faussaire et un fabricant d'images $(236 b-c)$ qui ne sont que simulacres trompeurs et subversifs des modèles. Semble ainsi se tisser un lien indissoluble entre l'image, la rhétorique fictionnelle du sophiste et la notion d'altérité qu'il serait intéressant d'exploiter dans ses nuances et implications aussi bien philosophiques que culturelles. Aristote va en quelque sorte simplifier cette conception de l'altérité (qui admet que chaque chose n'est pas seulement ce qu'elle est, mais une pluralité d'autres choses qu'elle n'est pas) en ne concevant l'Autre que relativement au même. Sur cette question, voir les réflexions de Nestor-Luis Cordero (" Du non-être à l'autre. La découverte de l'altérité dans le Sophiste de Platon ", Revue philosophique de la France et de l'étranger, 130, 2, 2005, p. 175 - 189) ainsi que les études réunies par Roger-Pol Drois (Figures de l'altérité, Paris, PUF, 2014), notamment l'article de F. Ildefonse ("Identité et altérité à partir des Bacchantes d'Euripide»). Aux modèles philosophiques offerts par Platon et Aristote, nous pourrions ajouter les deux modèles narratifs évoqués par T. Todorov (Nous et les autres, Paris, Seuil, 1989) - Hérodote et Homère - où l'altérité est pensée sur un rapport de distance géographique à l'Autre : le lointain comme dévalorisation de l'Autre et construction positive de l'identité nationale (Hérodote) vs/ le lointain comme point de fuite du désir conduisant à une critique de l'identité (Homère).

8. Article cité à la note 6 .

9. «L'altérité dans l'imaginaire occidental », p. 349.

10. Voir le passage de Paul Ricœur cité en exergue.

11. Ou, comme la désigne Denise Jodelet, cette « altérité du dehors [...] établi[e] en regard des critères propres à une culture donnée correspondant à une particularité nationale ou communautaire ou à une étape du développement social et technoscientifique » ("Formes et figures de l'altérité », in M. Sanchez-Mazas et L. Licata (dir.), L'Autre : regards psychosociaux, Grenoble, Les Presses de l'Université de Grenoble, 2005, p. 28).

12. Ou « altérité du dedans, référant à ceux qui, marqués du sceau d'une différence, quelle soit d'ordre physique ou corporelle $[\ldots]$, du registre des mœurs [...] ou liée à une appartenance de groupe [...], se distinguent à l'intérieur d'un même ensemble social ou culturel et peuvent y être considérés comme source de malaise ou de menace» (D. Jodelet, ibidem).

13. Celle-ci se caractérise en effet très souvent comme infinie commémoration du Même (le sacrifice des fils au nom de la perpétuation du Père, par exemple) et célébration, aux contours souvent très tranchés, des principes de la permanence et de l'immutabilité, de l'inhérence de la valeur, de la transmission généalogique ininterrompue depuis l'aube des temps de la propriété aussi des mots comme des choses, du primat de l'homogénéité et de continuité sur la discontinuité et la fragmentation, où la présence des 
reliques au sein même du discours, le style formulaire et volontairement archaïsant ainsi que l'imaginaire métonymique traduisent le désir d'exorciser tout écart (idéologique ou métaphorique) en faisant de la violence meurtrière face à l'Autre le lieu inexpugnable de la construction identitaire. Sur la grammaire de la chanson de geste, voir H. Bloch, Étymologie et généalogie. Une anthropologie littéraire du Moyen Âge français, Paris, Seuil, 1989, p. 126-173.

14. «Soi-même comme un autre suggère d'entrée de jeu que l'ipséité du soi-même implique l'altérité à un degré si intime que l'une ne se laisse pas penser sans l'autre, que l'une passe plutôt dans l'autre, comme on dirait en langage hégélien. Au « comme », nous voudrions attacher la signification forte, non pas seulement d'une comparaison - soi-même semblable à un autre -, mais bien d'une implication : soimême en tant que... autre »(P. Ricœur, Soi-même comme un autre, p. 14).

15. Voir ce concept chez Tertullien, notamment dans son fameux De cultu feminarum (II, 5, 2-4, par exemple). 16. Voir nos réflexions dans « Merlim, leitor de Tertuliano. Encontros (im)prováveis entre a gnose e a ficção na Idade Média ", Cadernos do CEIL. Revista Multidisciplinar de Estudos sobre o Imaginário, 1, 2011, p. 134-151: http://www.ceil.fcsh.unl.pt/cadernos/PDF/12_carlos_carreto2.pdf

17. Sur les rapports entre le masque et la métaphore, voir les réflexions de J.-M. Paquette : «Masque, songe et métaphore : le cas de la Chanson de Roland», in M.-L. Ollier (dir.), Masques et déguisements dans la littérature médiévale, Montréal/Paris, Les Presses de l'Université de Montréal/Vrin, 1988, p. 233-242. 18. Que l'on songe à la description de Tabur de Canaloine dans La Chanson de Guillaume ("Gros out la cors et l'eschine curbe,/ Lunges les denz, si est velu cun urse;/ Ne porte arme fors le bec et les ungles ", v. 3172-3174) ou à celle de la nourrice païenne et infanticide de la Bataille Loquifer: " Es la norrice, ses cors soit vergondés/ que plus est noire que aremens triblés;/ grant ot la gole, demi piet mesuré;/ de ses mamelles vos dirai verité,/ en .I. lit ot .VI. paien engendré;/ li .III. sont mort, et li .III. sont remés./ Chascons estoit de Maillefer ans né;/ sous qui sont mort ot a ses poinz tüés,/ et au .III. autres chascon les iolz crevés;/ de ses joiaus lor avoit ja mostré » (v. 4063-4072 de l'éd. M. Barnett, Oxford, Medium Aevum Monographs, 1975). Les exemples pourraient être multipliés à l'infini.

19. Les topoï (mais ne faut-il pas prendre toujours au sérieux ces lieux-communs comme espaces privilégiés où s'inscrit, dans l'envers du récit, le « sens au-delà du sens accessible », où loge, plus vive que jamais sous son apparente fixité, cette " l'image dans le tapis » évoquée par Alain Labbé - L'Architecture des palais et des jardins dans la chanson de geste, Paris/Genève 1987, p. 209 -, i.e., la profondeur imaginaire du récit) sont souvent polyvalents et multidirectionnels. Aussi, l'idolâtrie stigmatise-t-elle faussement aussi bien le Juif que le Sarrasin. Miroir inverse de l'exégèse chrétienne, l'idolâtrie désigne ici comme ailleurs une hypertrophie aveuglante du signifiant (littéral) par rapport au signifié. D'où le fait que l'Autre se caractérise par l'excès, le manque de jugement (ou de discernement) et l'obstination dans l'erreur. Sur la représentation du Sarrasin au Moyen Âge et dans le discours épique notamment, voir P. Bancourt, Les Musulmans dans les chansons de gestes du cycle du Roi, Aix en Provence-Marseille, 1982; Ph. Sénac, L'Image de l'autre. Histoire de l'Occident médiéval face à l'Islam, Paris, 1982 ; E. Filhol, «L'image des Sarrasins dans les textes chrétiens (de la Chanson de Roland à la Chronique du Pseudo-Turpin), in L'Occident musulman et l'Occident chrétien. Actes du Colloque International des 2, 3 et 4 novembre 1994 à Rabat, Rabat, 1995, p.223-39.

20. La légende de l'ivresse du prophète Mahomet, cause de sa mort déshonorante, est très vive dans la tradition épique du Moyen Âge. Nous en retrouvons l'écho notamment dans un passage du Moniage Rainouart I où le héros s'adresse au géant sarrasin Gadifer dans ces termes : "Es tu si faus que tu veus afichier/ que teus Dex vaille contre Dieu un denier/ qui se laissa estrangler el fumier » (v. 6787-6789 de l'éd. G. A. Bertin, Paris, Éditions A. \& J. Picard \& C Cie, 1973.

21. Voir, par exemple, les arguments pseudo-théologiques échangés lors de l'altercation entre Bertrand (le neveu de Guillaume) et le pauvre marchand de sel dans Le Charroi de Nîmes (v. 886-899 de l'éd. Duncan McMillan, Paris Klincksieck, 1978).

22. Sur cette question, je me permets de renvoyer à mes réflexions dans «Anatomie de la différence. Le corps déréglé et les outrances de l'écriture épique (XII ${ }^{\mathrm{e}}-\mathrm{XIII}{ }^{\mathrm{e}}$ siècles) ", Micrologus (Nature, Sciences and Medieval Societies), XX, 2012, p. 191-222. 
23. De par leurs résonnances agressives et une morphologie qui fait sans cesse miroiter la dimension du mal, du mensonge, du simulacre ou de la noirceur, les signifiants nominaux attribués aux sarrasins venus de terres étranges et ténébreuses (Marsile, Malduit, Corsabils, Malprimis de Brigal, Turgis, Escremiz de Valterne, Esturganz, Estramariz, Chernubles, Falsaron, Malsaron, Valdabrun, Abisme, Galafre, Valbrun, pour ne citer que quelques noms tirés de La Chanson de Roland) renvoient invariablement à un imaginaire de l'altérité placé sous le signe de l'angoisse, du monstrueux et de l'impropriété verbale qui contraste avec les noms propres lumineux des héros chrétiens. Lorsqu'il adopte le masque du marchand sarrasin dans Le Charroi de Nîmes, Guillaume d'Orange se fera nommer Tiacre, un signifiant nominal aux résonnances moins ténébreuses.

24. Les descriptions commencent toujours par insister sur cette partie du corps considérée par tous les traités (qu'ils soient de nature encyclopédique, médicale, théologique, normative ou philosophique) comme étant la plus noble : la tête, organe où siègent les forces de l'âme, symbole d'élévation, d'autorité et promesse de transcendance. Le gigantisme qui finit par contaminer tous les éléments constitutifs du corps (bras gros, jambes larges et voutées, pieds énormes et courbes [Gadifer], etc.), brisant toute symétrie et proportion, se manifeste ainsi tout d'abord par une remarquable hypertrophie des organes sensoriels : les yeux rouges et embrasés (Loquifer, Gadifer), qui parfois se démultiplient pour accroître les facultés visuelles ou dont la position s'inverse sur la syntaxe du corps, sont généralement recouverts de longues paupières, alors que la pilosité (cheveux, sourcils, longue barbe noir dans le cas spécifique de Loquifer, etc.) rapproche le géant de l'archétype de l'homme sauvage tout en soulignant une nature zoomorphe aux contours parfois mythiques (image du dragon), comme c'est le cas de Gadifer aux « jambes de serpantes » (hybridation qui relève de l'oxymore : Le Moniage Rainouart I, v. 6367 de l'éd. G. A. Bertin, Paris, A. \& J. Picard, 1973) dont l'extrémité affiche des « ongles agus comme serpens crestés » (v. 6141). La disproportion atteint également les oreilles sur lesquelles l'auteur de La Bataille Loquifer se plaît à surenchérir à propos du païn faé Ysabras qui ressemble alors étrangement aux Panotiens décrits par Isidore (Étymologies, XI, 3, 19-20) dont les oreilles sont si grandes qu'ils s'en servent pour envelopper/ protéger leur corps contre les adversités. Comme l'ogre ou l'avare, le champion sarrasin affiche toujours une bouche énorme et béante d'où émergent des dents coutelées " comme roncis » (MR I,v. 6137).

25. Voir à ce sujet les intéressantes réflexions du philosophe José Gil : Les Métamorphoses du corps, Paris, Éditions de La Différence, 1985 ; Monstros, Lisboa, Relógio d’Água Editores, 2006.

26. Voir B. Guidot (dir.), Burlesque et dérision dans les épopées de l'occident médiéval, Paris, Les Belles Lettres, 1995.

27. D'où l'extrême ambiguité qui fait du rire épique une " arme à double tranchant » qui trouble et transforme l'identité héroïque (A. Corbellari, « Guillaume face à ses doubles. Le Charroi de Nìmes, ou la naissance médiévale du héros moderne ", Poétique, 138, 2004, p. 142).

28. Tout comme dans la théologie apophatique, l'esthétique de la dissemblance ou de la difformité, devient, notamment sous l'influence des écrits du pseudo-Denys l'Aréopagite (voir le Livre des Noms divins, chap. IV et IX, par exemple), un moyen privilégié d'accéder à l'irreprésentable beauté (et harmonie) de la création divine et de restaurer la plénitude du signe et du sens. Que l'on songe, par exemple, à la diformis formositas ou à la formosa deformitas de la Création célébrée par Bernard de Clairvaux dans son Apologia ad Guillelmus Abbatem (III, 106), expressions qui pourraient, à elles seules, servir d'épitaphe à tous ces corps étranges qui, de plus en plus, peuplent l'art médiéval.

29. J.-Ch. Payen, « Une poétique du génocide joyeux : devoir de violence et plaisir de tuer dans la Chanson de Roland », Olifant, 6, 3-4, 1979, p. 226-236.

30. A. Leupin, «Raoul de Cambrai : la bâtardise de l'écriture », Romanic Revieww, 79, p. 100.

31. La problématique de l'espace est particulièrement intéressante au sein de la dialectique identité/ altérité dans la chanson de geste. En effet, s'agissant d'un territoire occupé, il se présente au guerrier épique comme l'espace d'une identité usurpée par l'Autre. L'imaginaire de la reconquête (par opposition à celui de la quête individuelle et initiatique qui caractérise le parcours du héros romanesque) assume alors souvent les contours d'une purification de l'espace identitaire par la violence extrême (politique de la terre brulée, pillages, massacres et conversions en masse) consistant à effacer tout vestige anxiogène de 
l'Autre. Néanmoins, aussi bien les textes que l'archéologie montrent que cette dynamique d'homogénéisation de ne se limite pas à produire un retour à l'identique, mais qu'elle participe plutôt d'une logique du palimpseste, de la réécriture, de la surimposition, où les vestiges (matériels, culturels, linguistiques) de la présence de l'Autre continuent à s'afficher sous les signes d'une identité dominante.

32. Pénétrer en territoire occupé en prenant les traits d'un Sarrasin, exige en effet que le héros chrétien parle (dans) la langue de l'Autre, le Sarrasinois que tous semblent maîtriser à la perfection.

33. Cette notion apparaît pour la première fois dans Temps et récit III et sera intégrée par Ricœur à un cadre épistémologique plus vaste reposant sur la théorie narrative dans Soi-même comme un Autre: «La notion d'identité narrative, introduite dans Temps et Récit III, répondait à une autre problématique : au terme d'un long voyage à travers le récit historique et le récit de fiction, je me suis demandé s'il existait une structure de l'expérience capable d'intégrer les deux grandes classes de récits. J'ai formé alors l'hypothèse selon laquelle l'identité narrative, soit d'une personne, soit d'une communauté, serait le lieu recherché de ce chiasme entre histoire et fiction. Selon la précompréhension intuitive que nous avons de cet état de choses, ne tenons-nous pas les vies humaines pour plus lisibles lorsqu'elles sont interprétées en fonction des histoires que les gens racontent à leur sujet ? Et ces histoires de vie ne sont-elles pas rendues à leurs tours plus intelligibles lorsque leur sont appliqués des modèles narratifs - des intrigues - empruntés à l'histoire proprement dite ou à la fiction (drame ou roman) ? Il semblait donc plausible de tenir pour valable la chaîne suivante d'assertions : la compréhension de soi est une interprétation ; l'interprétation de soi, à son tour, trouve dans le récit, parmi d'autres signes et symboles, une médiation privilégiée ; cette dernière emprunte à l'histoire autant qu'à la fiction, faisant de l'histoire d'une vie une histoire fictive, ou, si l'on préfere, une fiction historique, entrecroisant le style historiographique des biographies au style romanesque des autobiographies imaginaires. Ce qui manquait à cette appréhension intuitive du problème de l'identité narrative, c'est une claire compréhension de ce qui est en jeu dans la question même de l'identité appliquée à des personnes ou à des communautés. La question de l'entrecroisement entre histoire et fiction détournait en quelque sorte l'attention des difficultés considérables attachées à la question de l'identité en tant que telle " (Soi-même comme un autre, p. 138, note 1).

34. «Cette fonction médiatrice que l'identité narrative du personnage exerce entre les pôles de la mêmeté et de l'ipséité est essentiellement attestée par les variations imaginatives auxquelles le récit soumet cette identité. A vrai dire, ces variations, le récit ne fait pas que les tolérer, il les engendre, il les recherche. En ce sens, la littérature s'avère consister en un vaste laboratoire pour des expériences de pensée où sont mises à l'épreuve du récit les ressources de variation de l'identité narrative. Le bénéfice de ces expériences de pensée est de rendre manifeste la différence entre les deux significations de la permanence dans le temps, en faisant varier le rapport de l'une à l'autre. Dans l'expérience quotidienne, on l'a dit, elles tendent à se recouvrir et à se confondre ; ainsi, compter sur quelqu'un c'est à la fois faire fond sur la stabilité d'un caractère et s'attendre que l'autre tienne parole, quels que soient les changements susceptibles d'affecter les dispositions durables à quoi il se laisse reconnaître. Dans la fiction littéraire, l'espace de variations ouvert aux rapports entre les deux modalités d'identité est immense » (P. Ricœur, Soi-même comme un autre, p. 176).

35. P. Ricœur, Temps et récit III, Paris, Seuil, 198, p. 355 sq.

36. C'est notamment le cas dans la chanson de geste du XII' siècle Fierabras (laisses 122-124 de léd. M. Le Person, Paris, Champion, 2003) où le déguisement, outre le fait qu'il n'a ni l'ampleur ni la consistance narrative et symbolique qu'il exhibe dans un texte comme Charroi, est marqué par une certaine inefficacité, les Chrétiens étant immédiatement reconnus par les Sarrasins qui ont assiégé Aigremore, comme si le motif était réduit, dans ce poème, à une pure dimension topique.

37. P. Ricœur, Temps et récit III, p. 358.

38. C'est sous ce trait physionomique particulier que le héros est décrit dans le plus ancien fragment conservé de la tradition la Nota Emilianense - fragment de La Haye - de la fin du XI ${ }^{\mathrm{e}}$ siècle (Guigelmo alcorbinatas) ainsi que dans les premiers poèmes français (notamment dans Le Couronnement de Louis où Guillaume est dit al corb nes à la suite de l'amputation nasale infligée par le païen Corsolt qui menaçait le royaume de Louis). Sur cette question à la fois fascinante et complexe, je renvoie aux nombreuses études 
d'Alice Colby-Hall : "L'héraldique au service de la linguistique : le cas du 'cor nier' de Guillaume », Rencesvals, 10, 1987, p. 383-98; "In Search of the Lost Epics in the Lower Rhône Valley », Romance Epic, 1987, p. 115-25; «From Curb Niés to Cor Nier: The Linguistic Metamorphoses of William's Epic Nose », The Tenth Lacus Forum, 10, 1983, p. 505-15.

39. Situation fort plausible vu l'importance économique et politique du sel au Moyen Âge, le dynamisme des salines provençales entre le IX ${ }^{\mathrm{e}}$ et le XIII ${ }^{\mathrm{e}}$ siècle, et le fait que le commerce par voie terrestre (prépondérant jusqu'à la fin du Moyen Âge) se faisait à l'aide de mules, de chars à bœufs ou d'attelages de chevaux qui empruntaient l'ancienne Voie Domicienne reliant les principales villes du Midi dont Nîmes. Voir à ce sujet A. Venturini, «Le sel de Camargue au Moyen Âge. Étude comparative des pays d'Aigues-Mortes (Languedoc, royaume de France) et de Camargue proprement dite (comté de Provence, Empire) (ix ${ }^{\mathrm{e}} \mathrm{xv}^{\mathrm{e}}$ siècle) », in J.-C. Hocquet et J.-L. Sarrazin (dir.), Le Sel de la baie. Histoire, archéologie, ethnologie des sels atlantiques, Paris, Presses Universitaires de Rennes, 2006, p. 365-392.

40. R. Abdellatif; Y. Benhima; D. König; E. Ruchaud, «Introduction à l'étude des transferts culturels en Méditerranée médiévale. Aspects historiographiques et méthodologiques », in R. Abdellatif; Y. Benhima ; D. König ; E. Ruchaud (dir.), Construire la Méditerranée, penser les transferts culturels : Approches historiographiques et perspectives de recherche, Munich, Oldenbourg Verlag München, 2012, p. 14.

41. Picard, Ch. ; Balard, M., La Méditerranée au Moyen Âge, Paris, Hachette Éducation, 2014 ; Picard, Ch., La Mer des Califes. Une histoire de la Méditerranée musulmane (VII'-XII ${ }^{e}$ siècle), Paris, Seuil, 2015.

42. Nécromancie, machineries aux pouvoirs étranges, cultes des idoles, etc.). Le regard porté sur l'Autre par la chanson de geste est en effet très souvent teinté d'une secrète admiration qui nous invite, une fois de plus, à relativiser l'imaginaire manichéen et dichotomisant qu'on lui attribue si fréquemment. Les guerriers païens sont parfois l'emblème des vertus chevaleresques et courtoises au même titre (ou davantage encore) que les chevaliers chrétiens, doubles spéculaires parfaits que seule la religion (mais l'argument est de nature si figé dans la topique de la chanson de geste qu'il se dissipe facilement) permet de distinguer (Crucados, par exemple, un des nombreux champions sarrasins qui parsème la chanson d'Aliscans est décrit comme étant de « mout [...] bel semblant» (v. 6323). D'autre part, nous savons dès la Chanson de Roland (mais la tradition est sans doute bien plus ancienne et archaïque) que l'univers sarrasin est peuplé de somptueuses richesses qui s'offrent à la convoitise des Chrétiens, le royaume de l'Autre étant parfois dépeint comme un véritable Autre Monde, espace paradisiaque où tout devient possible, où tous les manques peuvent être comblés et tous les désirs idéalement satisfaits. Que l'on songe, par exemple, au royaume de Gaudisse (Babylone, située aux confins du monde connu) qu'Huon de Bordeaux, dans la chanson de geste éponyme, rejoint et conquiert après maintes péripéties : «Or prant [Huon] la voie ver le pallais listez./ Ens es vergiez l'amiralz est entrz./ Dieu ne fist arbre que fruit peüst porter/ Que on n'eüst ens es vergiez planteit./ Uen fontainne y sort per son channielz,/ De parraidis vint il ruix, san doubter » (v. 5659-5664 de l'éd. bilingue W. Kibler et F. Suard, Paris, Champion Classiques, 2003). Orange, la ville doublement convoitée (de par sa richesse et parce quelle abrite la belle Orable) est, elle aussi, décrite dans des termes semblables, tout comme la cité de Mecque que le roi Baudoin de Jérusalem se propose de conquérir dans Le Bâtard de Bouillon. Lunivers de l'Autre est également espace poétique et (u)topique où se mêlent admiration secrète et croyance dans le pouvoir admirable et menaçant qui émane du savoir détenu par les païens : nécromancie, objets aux vertus magiques qui ressoudent les corps et soignent toutes les plaies (que l'on songe aux propriétés du baume merveilleux que possède le géant sarrasin Loquifer dans la Bataille Loquifer ou dans Le Moniage Rainouart, identiques à celles que possèdent la pierre magique également dans Le Moniage Rainourt ou l'onguent préparé par Orable - devenue l'avatar épique d'Iseut la Blonde - dans les Enfances Guillaume), mais encore maîtrise mécanique du temps et de la nature à travers les automates. Toute synthèse à ce sujet étant difficile à établir, remarquons finalement que certains micro-récits étiologiques qui racontent la trajectoire subliminaire de certains objets prestigieux dont les héros chrétiens s'emparent témoignent d'une même admiration envers l'Autre sarrasin vu comme médiateur indispensable et donc structurant (tant du point de vue symbolique que narratif) au cœur de cette singulière translatio studii et imperii décrite par la circulation spatiale des objets auxquels il confère souvent une profondeur mythique. 
Forgée par un certain Irashels et achevée par le mythique Galan " qui un an le tempra » (v. 4165), d'où son nom, l'épée Recuite de La Chanson d'Antioche (qui réapparaitra dans la Bataille Loquifer aux mains du géant sarrasin) a, par exemple, appartenu à Alexandre, puis à Ptolémée et à Judas Macchabée, avant dêtre retrouvée par Vespasien (qui la dépose dans le saint Sépulcre) et conquise par les Sarrasins lors de la prise de Jérusalem.

43. Sur ces concepts théoriques qui traversent plusieurs champs du savoir (biologie, anthropologie, histoire), je renvoie à l'excellente synthèse de R. Abdella (et alii), « Introduction à l'étude des transferts culturels en Méditerranée médiévale ».

44. " Por un denier .ii. granz pains i preïsmes ;/ la deneree vaut .ii. en autre vile ;/ Molt par est bone se puis n'est enpirie » (v. 910-912).

45. Voir le passage de La Chanson Guillaume cité en exergue ainsi que le l'épisode d'Aliscans que nous retrouverons plus loin, où le héros épique, dominant une multiplicité impressionnante de langues, acquiert une dimension mythique qui le situe dans un temps archaïque pré-babélien ou qui le transporte, de l'autre côté du miroir biblique, vers une véritable Pentecôte du langage.

46. Voir la mise au point de J.-M. Schaeffer dans son ouvrage : Petite écologie des études littéraires. Pourquoi et comment étudier la littérature, Vincennes, Éditions Thierry Marchaisse, 2011, p. 83-103.

47. Stratégie trompeuse qui a longtemps fait croire que la chanson de geste était une histoire mythifiée alors qu'elle est davantage du mythe historicisé.

48. C'est ce qu'a parfaitement montré Alain Corbellari dans « Guillaume face à ses doubles ».

49. Voir, à ce sujet, les observations de J.-F. Kosta-Théfaine, « Le sel dans quelques poèmes d'Eustache Deschamps ", in V. Duché-Gravet et J.-G. Lapacherie (dir.), Du sel. Actes de la journée d'étude "Le sel dans la littérature française ", Biarritz, Éditions Atlantica, 2005, p. 29-48.

50. Traduit du latin par P. Monat, Grenoble, Éditions Jérôme Million, 2002. Intégré au livre des plantes (alors qu'Isidore en parle au sujet des produits sortant de la terre et de l'eau), les considérations sur le sel se trouvent aux pages 163-164.

51. Gervais de Tilbury, Le Livre des merveilles, trad. A. Duchesne, Paris, Les Belles Lettres, 2004.

52. L'expression est de Federico García Lorca, mais je l'emprunte, dans ce contexte précis, à J. Thomas : « Le 'chant profond' des mythes gréco-romains. États des lieux et perspectives méthodologiques », Cadernos do CEIL. Revista multidisciplinar de estudos sobre o imaginário, 1, 2011, p. 5-27 : https://ielt.fcsh.unl. $\mathrm{pt} /$ sites/ielt/conteudo/cadernosceil/ficheiros/n1/2_cj_thomas.pdf.

53. Sur l'importance du Carnaval dans le calendrier et l'imaginaire médiéval, voir Ph. Walter, Mythologie chrétienne. Fêtes, rites et mythes au Moyen Âge, Paris, Éditions Imago, 2005.

54. Le passage où les marchands vantent leurs produits est particulièrement éloquent : « Si li demandent: 'Quel avoir fetes traire ? " Nos, syglatons et dras porpres et pailes/ Et escarlates et vert et brun proisable,/ Tranchanz espiez et haubertz et verz heaumes,/ Escus pesanz et espee qui taillent " (v. 1063-1067). Remarquons, en effet, que les marchandises en question traduisent clairement l'identité des chevaliers à travers leur double statut de nobles (parures somptueuses) et de guerriers (les armes).

55. Description reprise par Guillaume aux vers 1139-1143.

56. L'argument brandi par Guiot, le neveu de Guillaume, dans La Chanson de Guillaume, pour expliquer pourquoi, contre les règles du combat singulier, il a tranché la tête du paien Desramé est révélateur : il s'agit de couper court, à travers un geste semblable à une castration, avec une généalogie proliférante du Mal incarné généralement par le sarrasin : "Ço respunt Guiot : 'Unc mais n’ö tel !/ S'il n'aveit pez dunt il peüst alet,/ il avoir oilz dunt il poeit veer,/ s'il aveit coilz pur enfant engendree'» (v. 1968-1971). 57. Cette asymétrie ou défaillance du langage comme signe d'élection ou de contact privilégié avec le sacré se retrouve bien entendu dans d'autres contextes mythiques et culturels.

58. Dans son célèbre Didascalicon, Hugues de Saint-Victor procède à un remarquable panégyrique du commerce (éloge qui contraste avec les nombreux discours théologiques, didactiques et moralistes qui, à la même époque, lancent toujours un soupçon sur l'économie marchande et monétaire) qu'il considère comme un véritable art civilisateur et comme emblème de l'éloquence (d'où l'analogie qu'il établit entre commerce et rhétorique ; analogie qui, à son tour, pourrait confirmer et renforcer la nature 
mercuriale de Guillaume, comme nous le verrons par la suite) : " La navigation contient toute espèce d'échange commercial consistant dans l'achat, la vente, l'échange des denrées nationales ou étrangères; on peut très justement la considérer, dans son genre, comme une sorte de rhétorique, puisque l'éloquence est particulièrement indispensable dans cette profession. Voilà pourquoi le maître du beau langage est appelé "Mercure", comme qui dirait "kirrius (Kyrios)", c'est-à-dire "seigneur" des marchands. La navigation pénètre les lieux secrets du monde, aborde des côtes jamais vues, parcourt des déserts horribles, et pratique le commerce de l'humanité avec des nations barbares, dans des langues inconnues. Sa pratique réconcilie les peuples, calme les guerres, affermit la paix et fait tourner les biens privés à l'utilité commune de tous » (L'Art de lire : Didascalicon, II, 23, trad. et notes de M. Lemoine, Paris, Cerf, 1991). 59. Voir la note 38 .

60. Héros paradoxal et fuyant du folklore et de la mythologie scandinave qui a posé de nombreux problèmes d'interprétation aux mythologues, Loki entretient lui aussi des rapports particuliers avec le monde chtonien et la métamorphose. Voir, à ce sujet, le dossier établi par G. Dumézil : Loki, in G. Dumézil, Mythes et dieux des Indo-Européens, Paris, Flammarion, 2011, p. 29-279.

61. "Mercurium sermonem interpretantur. Nam ideo Mercurius quasi medius currens dicitur appellatus, quod sermo currat inter homines medius (...). Ideo et mercibus praeesse, quia inter vendentes et ementes sermo fit medius. Qui ideo fingitur habere pinnas, quia citius verba discurrunt. Vnde et velox et errans inducitur (...). Nuntium dictum, quniam per sermonem omnia cogitata enuntiantur. Ideo autem furti magistrum dicunt, quia sermo animos audientium fallit. Virgam tenet, qua serpentes dividit, id est venena » (Isidore de Séville, Étymologies, VIII, 45-47 de l'éd. bilingue latin-espagnol de J. Oroz Reto et M.-A. Marcos Casquero, Mdrid, BAC, 1982). Quelques siècles plus tard, Jean Scot Érigène, confirme cette essence duelle de Mercure dans ses Annotationes in Marcianum : «La Fraude est dénommée ainsi parce qu'elle obéit souvent à Mercure. Mercure est dieu de léloquence parce qu'il se sert d'un grand nombre de ruses et de fraudes soit en bien soit en mal » (apud A. Leupin, Fiction et Incarnation : littérature et théologie au Moyen Âge, Paris, Flammarion, 1993, p. 93).

62. Une réaction violente qui souligne, sur le plan narratif et symbolique, l'identification pleine du héros au pauvre marchand de sel dont la vie dépendait justement de ces animaux précieux.

63. Les remarques d'A. Drzewicka (« Guillaume narrateur. Le récit bref dans Le Charroi de Nìmes », in Narrations brèves. Mélanges de littérature ancienne offerts à Krystyna Kaspryk, Varsovie, Publications de l'Université, 1993, p. 5-16) ne font que renforcer le statut narratif de l'identité que le masque épique met en scène. 64. A. Corbellari, « Guillaume face à ses doubles », p. 153-154.

65. « Guillaume face à ses doubles », p. 154.

66. "Le mythe de la bursa s'inscrit pour nous dans le cadre des liens symboliques qui rattachent la 'peau de vache' à la 'cité', à la fois dans la culture grecque et dans la culture romaine, La peau de vache est la cité, pourrait-on résumer ce mythe. Voilà le muthos, qui sous-tend de la même manière, par exemple, le rituel des Dipolies à Athènes, au cours duquel la peau du bovin sacrifié est bourrée de foin et remise sur pieds. L'association entre la vache et la cité est si bien établie qu'elle permet d'identifier, dans la construction de l'histoire d'Élissa, la présence d'une activité mytho-logique, où le mythe fait naître un récit » (La Tortue et la lyre. Dans l'atelier du mythe antique, Paris, Éditions du CNRS, 2014, p. 17).

67. Heur et malheur du guerrier. Aspects mythiques de la fonction guerrière chez les Indo-Européens, in G. Dumézil, Mythes et dieux des Indo-Européens, p. 295-296.

68. G. Dumézil, Ibid., p. 296.

69. À travers le sous-texte mythique, Guillaume parviendrait ainsi à accomplir ce qu'il promet sans cesse sous forme de menace, mais que l'éthos et l'imaginaire idéologique de la chanson de geste lui interdisent d'accomplir : détrôner le roi Louis.

70. Nous retrouvons ce motif (démuni toutefois de l'épaisseur symbolique et narrative qu'il acquiert dans les poèmes que nous venons de considérer) dans un autre texte structurant du Cycle de Guillaume, $L a$ Prise d'Orange, où c'est également à travers le masque sarrasin que les Chrétiens pénètrent dans la ville : «Fardoillé furent d'alun et d'arrement,/ Tres bien resemble Sarrasin ou tirant » (v. 452-453 de l'éd. Cl. Régnier, Paris, Klincksieck, 1986). 
71. Éd. Cl Régnier, vol. I, Paris, Champion, 1990.

72. Le poème Aliscans s'ouvre précisément sur ces vers : «Qui d'Aliscans ot les viers controvés/Ot tous ces mos perdus et desvoiés./ Ore les ra Guillaumes restorés [...] "(v. 37-38). Sur cette question, voir J. Cerquiglini-Toulet, La Couleur de la mélancolie. La fréquentation des livres au XIV siècle-1300-1415, Paris, Hatier, p. 106-108.

73. Ce que, nonobstant les multiples variations sur le thème, la plupart des prologues de romans et de chansons de geste n'ont de cesse de souligner.

74. Voir la note 41.

75. D'où le rôle régénérateur (à tous les points de vue) de Rainouart (le géant sarrasin élevé durant sept dans les cuisines du roi Louis) dès la seconde partie de La Chanson de Guillaume et d'Aliscans. Rainouart représente, par excellence, la figure de l'Autre et de la Différence qui vient racheter une identité épique gaste et saturée.

76. De noter encore que ce poème, tout en renforçant la fonction initiatique du retour à Orange sous l'égide du masque sarrasin ("Dex, dist li quens, com me velt esprover », v. 2977) et en soulignant sa nature potentiellement diabolique liée à une image décevante et trompeuse de l'Autre (« Cuida [le portier] qu'il fust de la gent l'averssier/ Qui le vousist traï et engignier ", v. 1963-1964), insiste davantage que La Chanson de Guillaume sur la souffrance du héros qui « de pitié plore » (v. 2024) face à l'insistant refus de sa femme à le reconnaître.

77. P. Ricœur, Soi-même comme un autre, p. 194. 